\title{
COMPARISON BETWEEN SPECTRAL, SPATIAL AND POLARIMETRIC CLASSIFICATION OF URBAN AND PERIURBAN LANDCOVER USING TEMPORAL SENTINEL - 1 IMAGES
}

\author{
K. Roychowdhury* \\ Department of Geography, Presidency University, Kolkata 700073, India - koel.geog@presiuniv.ac.in
}

ThS 3: Sentinel-1 Radar

KEY WORDS: Sentinel - 1, Urban, Polarimetry, Texture, Classification, Landcover

\begin{abstract}
:
Landcover is the easiest detectable indicator of human interventions on land. Urban and peri-urban areas present a complex combination of landcover, which makes classification challenging. This paper assesses the different methods of classifying landcover using dual polarimetric Sentinel-1 data collected during monsoon (July) and winter (December) months of 2015. Four broad landcover classes such as built up areas, water bodies and wetlands, vegetation and open spaces of Kolkata and its surrounding regions were identified. Polarimetric analyses were conducted on Single Look Complex (SLC) data of the region while ground range detected (GRD) data were used for spectral and spatial classification. Unsupervised classification by means of K-Means clustering used backscatter values and was able to identify homogenous landcovers over the study area. The results produced an overall accuracy of less than $50 \%$ for both the seasons. Higher classification accuracy (around $70 \%$ ) was achieved by adding texture variables as inputs along with the backscatter values. However, the accuracy of classification increased significantly with polarimetric analyses. The overall accuracy was around $80 \%$ in Wishart H-A-Alpha unsupervised classification. The method was useful in identifying urban areas due to their double-bounce scattering and vegetated areas, which have more random scattering. Normalized Difference Built-up index (NDBI) and Normalized Difference Vegetation Index (NDVI) obtained from Landsat 8 data over the study area were used to verify vegetation and urban classes. The study compares the accuracies of different methods of classifying landcover using medium resolution SAR data in a complex urban area and suggests that polarimetric analyses present the most accurate results for urban and suburban areas.
\end{abstract}

\section{INTRODUCTION}

Globally around $54 \%$ of people were living in urban areas in 2014 and the figure is predicted to be around $66 \%$ by 2050 (Department of Economics and Social Affairs, 2014). Urban and suburban areas are undergoing fast changes in landcover. Monitoring of landcover changes are essential not only for regional and global scale modeling, but also for planning, management of resources and development of an area. Extensive researches have been carried out to study landcover changes using earth observation techniques (Bhatta, Saraswati, \& Bandyopadhyay, 2010a, 2010b; Blaschke, 2010; Sole et al., 2011; Taubenböck, Roth, \& Dech, 2007; Taubenböck, Wegmann, Roth, Mehl, \& Dech, 2009).. Methods of identification varied from supervised classification (Chen \& Douglas, 2002; Wang, 1990) to object oriented methods (Blaschke, 2010; H Taubenböck, Esch, Wurm, Roth, \& Dech, 2010) and sub-pixel analyses (Mitraka, Chrysoulakis, Kamarianakis, Partsinevelos, \& Tsouchlaraki, 2012; Powell, Roberts, Dennison, \& Hess, 2007; Yang, Xian, Klaver, \& Deal, 2003). However, optical images suffer from some drawbacks such as poor data capture due to cloud cover and haze. These pose difficulties in identifying seasonal variations of landuses. Therefore, data obtained by the methods of active remote sensing such as LIDAR (Antonarakis, Richards, \& Brasington, 2008; Chena, Su, Lia, \& Sun, 2009) and RADAR (Dobson, Ulaby, \& Pierce, 1995; Lee, Grunes, \& Pottier, 2001) are recently becoming popular for classification of landcover. These data have all weather capability and are useful for identifying structural elements of landcover in an area.
Early studies that employed radar remote sensing to investigate landuse/landcover information were mainly performed using space shuttle SIR-C/X-SAR (Pierce, Bergen, Dobson, \& Ulaby, 1998; Saatchi, Soares, \& Alves, 1997). Airborne radar imagery systems also provided data for landuse/landcover mapping (Yeh \& Qi, 2015). However, they are only occasionally launched to collect experimental data within a very short period. Regular investigation of timely landuse/landcover information using radar remote sensing has become practicable only after successful operation of orbital radar systems with SAR. These included ERS-1 and ERS-2, JERS-1, RADARSAT-1, TerraSAR-X, RISAT-1 and Sentinel-1. These are made available for regular data collection (Yeh \& Qi, 2015).

Initial studies for landuse/landcover mapping used SAR single frequency data. These created confusions in separation and mapping of landuse/landcover classes It stemmed from limited information obtained by single-frequency systems (Li \& Yeh, 2004; Ulaby, Kouyate, Brisco, \& Williams, 1986). To overcome this difficulty, researchers started utilizing polarimetric SAR (PolSAR) data to study landuse/landcover information (Du \& Lee, 1996; Freitas et al., 2008; Lee, Grunes, \& Pottier, 2001; Pierce, Ulaby, Sarabandi, \& Dobson, 1994). The results showed that PolSAR measurements achieved much better classification results than single polarization SAR (Biro, Pradhan, Sulieman, \& Buchroithner, 2013; Qi, Yeh, Li, \& Zhang, 2015; Yeh \& Qi, 2015). 
PolSAR data were mainly used for mapping landuse/landcover in river catchments (Ahmed, Garg, Singh, \& Raman, 2014) and flood affected areas (Manavalan, Rao, Krishna Mohan, Venkataraman, \& Chattopadhyay, 2013). Later, this data have also been used successfully in urban areas (Gamba \& Aldrighi, 2012; Niu \& Ban, 2013; Werner, Storie, \& Storie, 2014). Several methods were implemented to identify urban landuse/landcover classes. Some of these methods are supervised classification from backscatter and coherence (Parihar, Das, Rathore, Nathawat, \& Mohan, 2014), unsupervised classification (Ince, 2010), object-oriented image analysis, change vector analysis, post-classification comparison (Biro et al., 2013; Qi et al., 2015), change detection matrix (Lê, Atto, Trouvé, Solikhin, \& Pinel, 2015), polarimetric decomposition, Pol- SAR interferometry, and decision tree algorithms (Qi, Yeh, Li, \& Lin, 2012). Fusion of optical and SAR images also proved to be a useful method in urban landuse/landcover classification. These mainly included normalization techniques (Zhang, 2015) and image segmentation (Gamba \& Aldrighi, 2012).

For the continuation and improvement of SAR applications, the European Space Agency (ESA) launched an European Radar Observatory consisting of a polar orbiting two-satellite constellation (Sentinel-1) (Torres et al., 2012). The satellite has a revisit period of 12 days at the equator. The near polar, circular orbit of the spacecraft at an elevation of $693 \mathrm{Km}$ is sunsynchronous with an inclination of $98.18^{\circ}$ (Sentinel-1 Team, 2013). The centre frequency of the data captured is $5.405 \mathrm{GHz}$ i.e. the data is collected in the C-band of the electromagnetic spectrum. The incidence angle varies from $20^{\circ}$ to $45^{\circ}$. Data obtained from this satellite can meet explicit research needs relating to land, ocean and cryosphere (Malenovský et al., 2012). Sentinel-1 data has been used in different researches since the time of its availability. The data has been applied in researches on disaster management (Plank, 2014) and areas undergoing rapid changes in a wetland environment (Muro et al., 2016). This data has been widely applied for landcover mapping. It was used for generating level - 2 landcover products along with temporal ERS-2 and ENVISAT ASAR AP C-band data (Thiel et al., 2009). INSAR coherence was used for landuse classification and monitoring of temporal changes (Wegmuller, Santoro, Werner, \& Cartus, 2015).

The current study assesses different methods of landcover classification in an urban area using Sentinel - 1 data. Unsupervised classification by K-means clustering, supervised classification by Maximum Likelihood method and Wishart $\mathrm{H}-$ A-Alpha polarimetric decomposition methods were examined. The major objective of this research is to identify the most appropriate method of landcover classification using multitemporal SAR data to discriminate broad landcover classes in urban and peri-urban areas of an expanding metropolis

\section{STUDY AREA}

The study is based on the city of Kolkata and its surrounding areas. Kolkata is the third largest metropolis of India with a population of 4.5 million. The city is located in the eastern banks of river Hugli. Due to large-scale migration from adjacent rural areas and immigration from the neighbouring country of Bangladesh, the city is experiencing growth for the last few decades. Due to the presence of river Hooghly on the western side of the city, Kolkata mostly experiences a north south sprawl. The city and its surrounding areas are undergoing rapid changes due to construction of new residential areas, roads and flyovers. As a result large scale agricultural lands are getting converted to non-agricultural uses. Kolkata and its surrounding areas are represented in Figure 1.

\section{DATA USED}

Sentinel-1 datasets were downloaded from the data hub of Sentinel. The data were acquired on 24th of July and 15th of December 2015. Level-1 SLC and GRD data were used in this study. The datasets were chosen to match with the wet and the dry seasons of the year. Both the datasets had dual polarization capabilities; vertical transmit and horizontal receive (VH) and vertical transmit and vertical receive (VV). Single Look Complex (SLC) products were geo-referenced using orbit and attitude data from the satellite. They were provided in zeroDoppler slant-range geometry and consisted of complex samples preserving the phase information. Ground Range Detected (GRD) products, on the other hand, were focused SAR data detected, multi-looked and projected to ground range using an earth ellipsoid model. Phase information was absent in these products. (Sentinel-1 Team, 2013). Data captured in the Interferometric Wide Swath Mode (IW) were used in this research. These datasets have a swath of $250 \mathrm{Km}$ and spatial resolutions of 5 X $20 \mathrm{~m}$ (Sentinel-1 Team, 2013).

Landsat 8 data collected during the month of March 2015 was used to calculate NDVI and NDBI. These were used to validate the extents of urban built up areas and vegetation as obtained from the classification of SAR images.

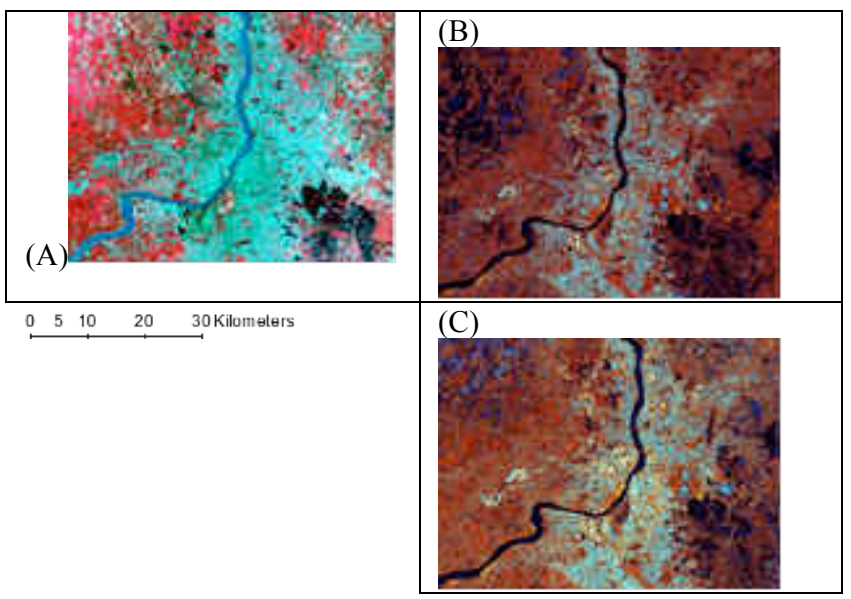

Figure 1: Study Area: (A) Landsat 8 image (band 5, band 4, band 3); (B) 24th July, 2015 (VH, VV, VV/VH); (C) 15th December, 2015 (VH, VV, VV/VH)

\section{METHOD}

The method followed in this research was divided into four parts: classification of GRD data, processing of Landsat8 data, polarimetric classification of SLC data and accuracy assessment.

\subsection{Processing of GRD Data}

The GRD datasets of both monsoon and winter seasons were radiometrically calibrated to obtain sigma nought $\left(\sigma^{\circ}\right)$ or the backscatter values. The process of multilooking was used to convert the images from slant range to ground range. During this process the image pixels became approximately square spaced. Refined Lee filter with an edge threshold of 5000.00 were applied on the images to reduce the noise from random constructive and destructive interferences. Finally both the 
images were terrain corrected. This process geocoded the images by correcting the SAR processing distortions using a Digital Elevation Model (DEM). In this case, SRTM 3sec DEM was used. The resultant images were projected by default to Geographic Latitude/Longitude projection (Array Systems Computing and ESA, 2015).

Kolkata and its surrounding suburban areas were subset from the orthorectified images for further analyses. The bands with $\mathrm{VH}$ and VV polarizations were layer stacked and classification was done on the resultant image. Backscatter values $\left(\sigma^{\circ}\right)$ were used for identifying the classes. Two methods of classification were undertaken. In the first step a K-Means clustering method was used for classification (Lillesand, Kiefer, \& Chipman, 2004). For the convenience of classification, a minimum of 10 and a maximum of 20 classes were initially set for the K-Means algorithm with a change threshold percentage of $99 \%$. The resultant classes were merged to produce the final four major landcover classes: water and wetlands, open spaces, urban built up areas and vegetation. Next, a maximum likelihood supervised classification was also performed on the backscatter images. Training sample datasets were created. The images were then classified using the training samples.

In the next step, texture elements were calculated using the Grey Level Co-occurrence Matrix (GLCM) algorithm. These included contrast, dissimilarity, homogeneity, angular second moment, mean, variance, correlation and entropy. The backscatter images were merged with the texture elements. These merged images were then classified using K-Means clustering unsupervised method. Four landcover classes (water bodies and wetlands, open land, vegetation and urban built-up areas) as previous steps were identified to facilitate comparison of results.

\subsection{Processing of Landsat 8 data}

A cloud free Landsat 8 imagery from March 2015 over Kolkata was downloaded from the USGS Website. The data was also used to prepare NDVI and NDBI maps of the study area. NDVI is calculated as:

$$
\frac{N I R-R}{N I R+B}
$$

Where,

$$
\begin{aligned}
& \mathrm{NIR}=\text { Near Infra-Red band } \\
& \mathrm{R}=\text { Red band }
\end{aligned}
$$

For Landsat 8 , this was obtained by the following ratio:

$$
\text { Band } 5-B \text { and } 4
$$

NDBI is calculated as

$$
: \frac{R 1650-R 830}{R 1650+R 830}
$$

For Landsat 8 , this was calculated from:

$$
\text { Band } 6-B \text { and } 5
$$

\subsection{Processing of Single Look Complex (SLC) data}

In the first step, covariance matrices (C2) were calculated for both the images. It is a measure of the power of the received signal. $\mathrm{C} 2$ is expressed as:

$$
C=K_{L} K_{L}^{* T}
$$

where, $K_{L}=\left(\begin{array}{c}S_{H H} \\ \sqrt{2} S_{H V} \\ S_{V V}\end{array}\right)$ and $\mathrm{S}$ is the scattering matrix.

Entropy (H), anisotropy (A) and alpha ( $\alpha$ ) images were obtained for both the time periods. Entropy $(\mathrm{H})$ is a measure of dominance of a certain scattering mechanism in a given resolution cell of the image. It varies from 0 to 1 . A value of 0 identifies that all scattering comes from one mechanism (such as flat surface or a tall building by double bounce), while a value of 1 represents a completely random scattering mechanism. Anisotropy (A), on the other hand is a measure of homogeneity of a target relative to the radar look direction. The value of anisotropy also varies from 0 to 1 . It becomes 0 if both scattering mechanisms are of an equal proportion. A value greater than 0 represents more anisotropic scattering. Thus anisotropy is complementary to entropy. However, it can be used as a source of decomposition only when $\mathrm{H}>0.7$. Alpha $(\alpha)$ angle provides the nature of dominant scattering mechanism for a resolution cell if the entropy value is 0 for the said cell. Alpha values identify if the scattering is volume, surface or double bounce. The angle is normalized between $0^{\circ}$ and $90^{\circ}$. Alpha angle close to zero indicates surface scattering. As it increases from 0 , it approaches to volume or multiple scattering at $\alpha=45^{\circ}$ and then it approaches to double bounce scattering till $\alpha=90^{\circ}$.

Landcover classes of the study area were identified by Wishart H-A- $\alpha$ classification. This method used the Entropy $(H)$, Anisotropy (A) and Alpha $(\alpha)$ as inputs. Sixteen classes were initially generated which were merged to four landcover classes (water bodies and wetlands, open land, vegetation and urban built-up areas).

\subsection{Accuracy Assessment}

Hundred ground reference points were randomly collected from the study area for assessing the accuracy of classification. Confusion matrix, producer's accuracy and user's accuracy were calculated for all three types of classification.

\section{RESULTS AND DISCUSSIONS}

The outputs from analyses are explained using the results from accuracy assessment. They are divided under the following categories:
i. Unsupervised and supervised classification of backscatter image
ii. Classification using texture data
iii. Polarimetric analyses and classification
iv. Comparison with Landsat data

\subsection{Unsupervised and Supervised Classification of Backscatter images}

The overall accuracies of classification of GRD data are less than $50 \%$ for both supervised and unsupervised classifications. The user's and producer's accuracies from the classifications are presented in table 1. Producer's accuracy indicates how well the training set pixels of a given class is classified. The user's accuracy, on the other hand, indicates the probability that a pixel classified into a given class actually belongs to the said class on the ground. The urban landcover category exhibited varying accuracies in the classification. The highest user's accuracy for urban built up areas was obtained from supervised classification of the image collected on $15^{\text {th }}$ December. 


\begin{tabular}{|l|l|l|l|l|l|l|l|l|}
\hline & \multicolumn{2}{|l|}{ 24J (K) } & \multicolumn{2}{|l|}{ 24J (S) } & \multicolumn{2}{l|}{ 15D (K) } & \multicolumn{2}{|l|}{ 15D (S) } \\
\hline & PA & UA & PA & UA & PA & UA & PA & UA \\
\hline $\begin{array}{l}\text { Water } \\
\text { bodies }\end{array}$ & 41 & 70 & 100 & 70 & 41 & 70 & 47 & 80 \\
\hline $\begin{array}{l}\text { Open } \\
\text { Space }\end{array}$ & 28 & 35 & 29 & 20 & 24 & 20 & 67 & 69 \\
\hline Vegetation & 61 & 41 & 60 & 50 & 67 & 33 & 68 & 38 \\
\hline $\begin{array}{l}\text { Urban and } \\
\text { Built up } \\
\text { Areas }\end{array}$ & 36 & 50 & 32 & 69 & 28 & 69 & 48 & 75 \\
\hline
\end{tabular}

Table 1: Accuracy Assessment; PA: Producer's Accuracy; UA: User's Accuracy; 24J: 24th July; 15D: 15th December; (K): K-Means Clustering; (S): Supervised classification

For the supervised classification on the $24^{\text {th }}$ July data, the user's accuracy of urban built up class was around $69 \%$. The lowest user's accuracy for the same class was noted in the unsupervised classified image of $24^{\text {th }}$ July. However relatively low producer's accuracies were obtained for the urban class suggesting significant omission errors for this class. Comparatively higher user's accuracies were also noted for the water landcover class. The producer's accuracy for the water class was $100 \%$ in the supervised image of $24^{\text {th }}$ July. Both the producer's and user's accuracies are low for open space landcover class indicating high omission and commission errors for this class. Overall, the classifications produced mixed results.

\subsection{Classification using Texture Data:}

Unsupervised classification (K-Means) was conducted on the images with texture variables. The overall accuracies increased to $59 \%$ for the winter month and $70 \%$ for the monsoon month. The producer's and user's accuracies for the classification are presented in table 2 .

\begin{tabular}{|l|l|l|l|l|}
\hline & \multicolumn{2}{|l|}{ 24J (T) } & \multicolumn{2}{l|}{ 15D (T) } \\
\hline & PA & UA & PA & UA \\
\hline $\begin{array}{l}\text { Water } \\
\text { bodies }\end{array}$ & 86 & 60 & 47 & 80 \\
\hline $\begin{array}{l}\text { Open } \\
\text { Space }\end{array}$ & 55 & 80 & 67 & 69 \\
\hline Vegetation & 85 & 65 & 68 & 38 \\
\hline Urban and Built up Areas & 54 & 76 & 48 & 75 \\
\hline
\end{tabular}

Table 2: Accuracy Assessment; PA: Producer's Accuracy; UA: User's Accuracy; 24J: 24th July; 15D: 15th December; (T): Texture Image

It was observed that the user's accuracies significantly increased in this method of classification compared to the results in the section 5.1. For the month of July, the user's accuracies for water bodies, open spaces, vegetation and built up areas were respectively $60 \%, 80 \%, 65 \%$ and $76 \%$. The same from the classification of backscatter image were $70 \%, 35 \%$, $40.74 \%$ and $50 \%$ respectively. Only the accuracy for the water class decreased in the classification of the texture image. For all the other classes, there was an increase in accuracy by more than $20 \%$. For the month of December, the user's accuracies from classification of the texture image were $80 \%, 68.57 \%$, $38.46 \%$ and $75 \%$ respectively for water, open space, vegetation and urban built up areas respectively. From the backscatter image these values were $70 \%, 20 \%, 33.33 \%$ and $68.75 \%$ respectively. The accuracy for the open space class increased by more than $48.5 \%$ in the texture image classification compared to that from backscatter image. Overall, the incorporation of the texture bands increased the classification accuracies of all the landcover categories

\subsection{Polarimetric Analyses and Classification}

In the next step entropy, anisotropy and alpha were calculated for both the images. The $\mathrm{H}-\alpha$ segmented planes are presented in fig 2 . The $\mathrm{x}$-axis shows the entropy values while the y axis is representing the alpha values. Areas with low entropy $(0-0.5)$ and low alpha ( 0 to less than $\left.45^{\circ}\right)$ are denoting water. Areas with low entropy and multiple scattering are denoted in lighter blue. Lighter green portions of the graph are representing areas with medium entropy surface scattering. Medium entropy with dipole scattering are representing the trees in the study area. They are clustered in orange in the segmented planes. Low entropy surface scattering denoting rough areas are shown in darker shade of green. Areas with low entropy and dipole scattering are shown in dark red.

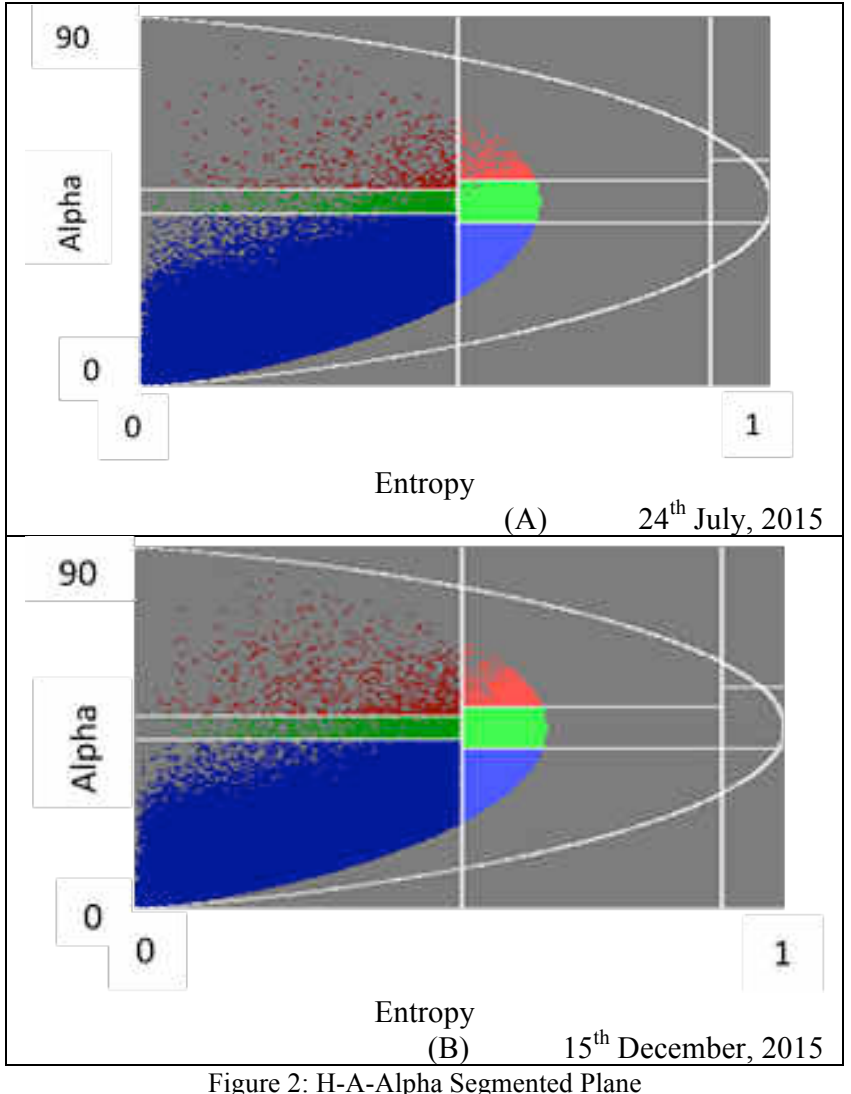

Surface scattering in the study area are represented by the blue portion of the graph with alpha values less than 40 degrees. Volume scattering from features are shown in the green part where alpha varies from 40 to 45 degrees. Areas with alpha values more than 45 degrees have multiple scattering and are shown in red.

The inputs from entropy, anisotropy and alpha were used for Wishart H-A- $\alpha$ classification of both the images. The overall classification accuracies significantly increased to $79 \%$ for the monsoon month and $81 \%$ for the winter month. 


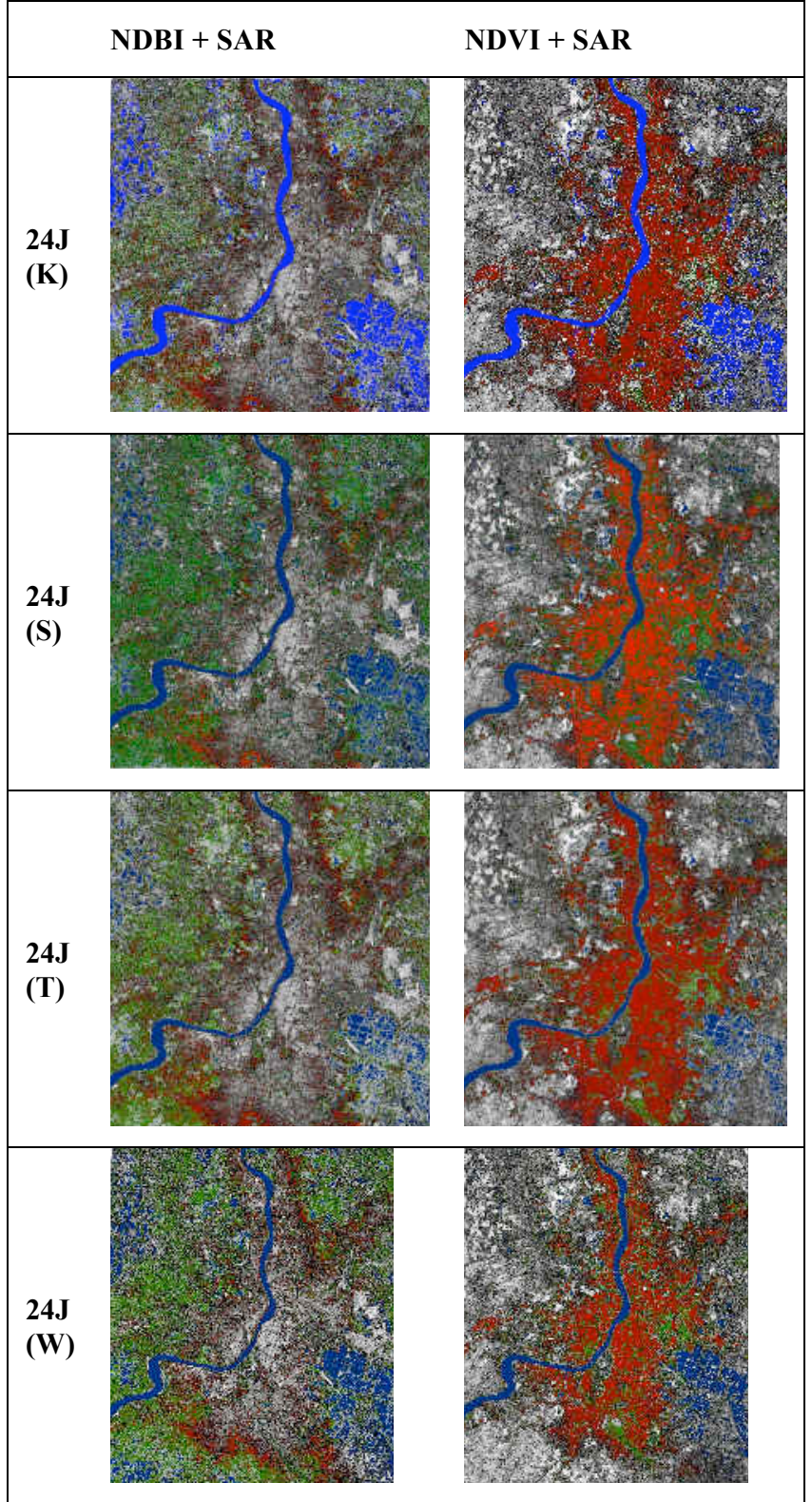

Figure 3: Combination of NDBI and NDVI with Sentinel-1 data classified images; 24J: 24th July; (K): K-Means clustering; (S): Supervised classification; (T): Texture image; (W): Wishart H-A-Alpha classification

The user's and producer's accuracies for the classification are presented in table 3. The user's accuracy of urban built-up areas and open spaces increased to $100 \%$ for the image captured on $24^{\text {th }}$ July. This shows that pixel classified as these two classes actually belong to the said classes on the ground. The accuracy was also $100 \%$ for built up areas and $90 \%$ for open spaces in the image captured on $15^{\text {th }}$ December. The user's accuracy for vegetation was $74 \%$ for winter and $65 \%$ for the month of monsoon. The producer's accuracies were also high for all the classes. For the vegetation class, it was $100 \%$ for the monsoon month and $95 \%$ for winter. The producer's accuracy was also $100 \%$ for water bodies during monsoon. Thus the sample pixels have been well classified for these two classes. Overall, there was marked improvement in classification by polarimetric analyses.

\subsection{Comparison with Landsat Image}

The NDVI and NDBI images obtained from Landsat 8 data were then compared with the classified Sentinel-1 products. Vegetation appears brighter in the former one while the built up areas are lighter in the latter. In figures 3 and 4, columns I show the combination of NDBI and classified SAR images while columns II represent overlapping NDVI and SAR classification.

\begin{tabular}{|l|l|l|l|l|}
\hline & \multicolumn{2}{|l|}{ 24J (W) } & \multicolumn{2}{l|}{ 15D (W) } \\
\hline & PA & UA & PA & UA \\
\hline $\begin{array}{l}\text { Water } \\
\text { bodies }\end{array}$ & 100 & 80 & 100 & 70 \\
\hline $\begin{array}{l}\text { Open } \\
\text { Space }\end{array}$ & 66 & 100 & 67 & 90 \\
\hline Vegetation & 100 & 65 & 95 & 74 \\
\hline $\begin{array}{l}\text { Urban and Built up } \\
\text { Areas }\end{array}$ & 62 & 100 & 67 & 100 \\
\hline
\end{tabular}

Table 3: Accuracy Assessment; PA: Producer's Accuracy; UA: User's Accuracy; 24J: 24th July; 15D: 15th December; (W): Wishart H-AAlpha classified image

In figures 3 and 4 , most of the red pixels (built up areas) in column I have coincided with the urban areas from Landsat data. Some non-overlapping red areas are visible in the south and north east part of the region. These are suburban areas and also represent mixed landuse types. Comparisons with NDVI image (column II in figures 3 and 4), revealed that vegetation and open spaces were quite successfully identified in Sentinel-1 data. However, a built up area in the eastern part of the study area was erroneously classified as vegetation in most of the instances. This part is a planned satellite town of Kolkata and therefore have many planted vegetation. Combination of built up areas and vegetation makes identification difficult.

\section{CONCLUSION}

The present study used temporal Sentinel-1 dual polarimetric SAR data to identify four broad landcover classes of Kolkata and surrounding areas. The data were chosen for monsoon and winter months. It was observed that using unsupervised and supervised classification the image classification accuracy was less than $50 \%$ for both the seasons. The methods used backscatter values as inputs for identifying classes. Texture variables could improve the classification accuracy to around $70 \%$. Highest accuracy (around 80\%) could be achieved by polarimetric classification. Overall, the classification coincided well with the NDBI and NDVI images obtained from Landsat 8 data. Seasonal comparison of classification revealed that features were better identified and classified for the monsoon month than winter season. One of the probable reasons was that during the month of July the water bodies could be conveniently identified due to high specular reflections. Areas with multiple scattering are high in winter because of the lack of moisture in the area. This makes distinct identification of landcover classes difficult in an urban environment. Thus, the current research has established the utility of Sentinel-1 SAR data in landcover classification. It has also compared the different methods of classification and established that texture data combined with backscatter values are more useful in feature identification from SAR data. But polarimetric decompositions using surface scattering of SAR data is the most accurate method for landcover classification in urban and peri-urban areas. 


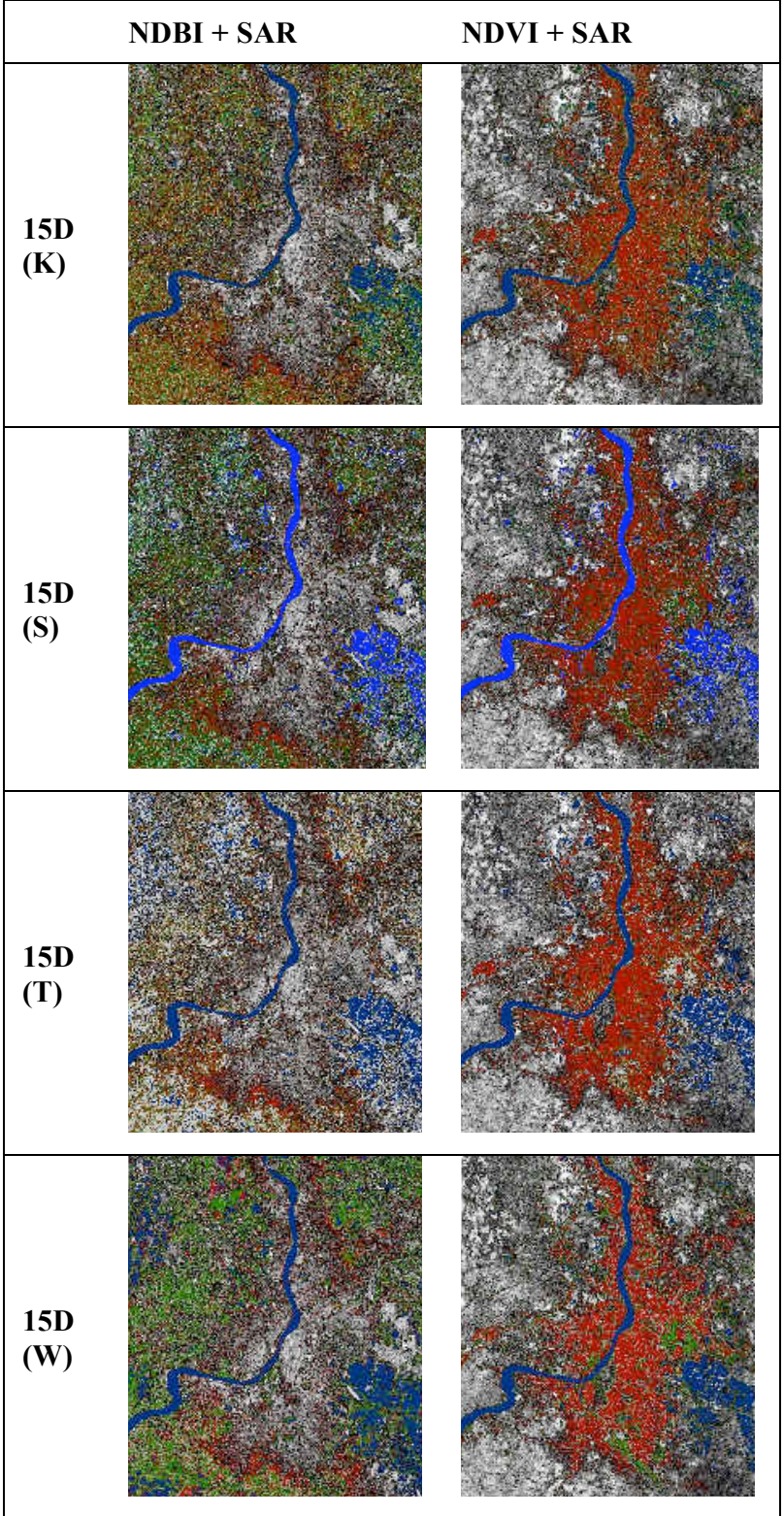

Figure 4: Combination of NDBI and NDVI with Sentinel-1 data classified images; 15D: $15^{\text {th }}$ December; $(\mathrm{K})$ : K-Means clustering; (S): Supervised classification; (T): Texture image; (W): Wishart H-A-Alpha classification

\section{REFERENCES}

Ahmed, Tasneem., Garg, Akanksha., Singh, Dharmendra., \& Raman, Balasubramanian. (2014, 2014). An approach to monitor river catchment with PAL SAR satellite data. Paper presented at the 9th International Conference on Industrial and Information Systems (ICIIS).

Antonarakis, A. S., Richards, K. S., \& Brasington, J. (2008). Object-based land cover classification using airborne LiDAR. Remote Sensing of Environment, 112(6), 2988 - 2998.

Array Systems Computing and ESA. (2015). Sentinel-1 Toolbox: SAR Basics Tutorial.

Bhatta, B., Saraswati, S., \& Bandyopadhyay, D. (2010a). Quantifying the degree-of-freedom, degree-of-sprawl, and degree-of-goodness of urban growth from remote sensing data. Applied Geography, 30(1), 96-111.

Bhatta, B., Saraswati, S., \& Bandyopadhyay, D. (2010b). Urban sprawl measurement from remote sensing data. Applied Geography, 30(4), 731-740.

Biro, Khalid, Pradhan, Biswajeet, Sulieman, Hussein, \& Buchroithner, Manfred. (2013). Exploitation of TerraSAR-X data for land use/land cover analysis using object-oriented classification approach in the African Sahel Area, Sudan. Journal of the Indian Society of Remote Sensing, 41(3), 539553.

Blaschke, T. (2010). Object based image analysis for remote sensing. ISPRS Journal of Photogrammetry and Remote Sensing, 65(1), 2-16. http://doi.org/10.1016/j.isprsjprs.2009.06.004

Chen, D., \& Douglas, S. (2002). The effect of training strategies on supervised classification at different spatial resolutions. Photogrammetric Engineering and Remote Sensing, 68(11), $1155-1162$.

Chena, Y., Su, W., Lia, J., \& Sun, Z. (2009). Hierarchical object oriented classification using very high resolution imagery and LIDAR data over urban areas. Remote Sensing of Environment, 43(7), $1101-1110$.

Department of Economics and Social Affairs, P. D. (2014). World Urbanization Prospects: The 2014 Revision, Highights. United Nations.

Dobson, M. C., Ulaby, F. T., \& Pierce, L. E. (1995). Land-cover classification and estimation of terrain attributes using synthetic aperture radar. Remote Sensing of Environment, 51(1), 199 214.

Du, L., \& Lee, J. S. (1996). Fuzzy classification of earth terrain covers using complex polarimetric SAR data. International Journal of Remote Sensing, 17(4), 809 - 826.

Freitas, C.D., Soler, L. D., Anna, S. J. S. S., Dutra, L.V., dos Santos, J. R., Mura, J. C., \& Correia, A. H. . (2008). Land use and land cover mapping in the Brazilian Amazon using polarimetric airborne p-band SAR data. IEEE Transactions on Geoscience and Remote Sensing, 46(10), 2956 - 2970.

Gamba, Paolo, \& Aldrighi, Massimiliano. (2012). SAR data classification of urban areas by means of segmentation techniques and ancillary optical data. Selected Topics in Applied Earth Observations and Remote Sensing, IEEE Journal of, 5(4), 1140-1148.

Ince, Turker. (2010). Unsupervised classification of polarimetric SAR image with dynamic clustering: An image processing approach. Advances in Engineering Software, 41, $636-646$.

Lê, Thu Trang., Atto, Abdourrahmane. M., Trouvé, Emmanuel. Solikhin, Akhmad. \& Pinel, Virgine. (2015). Change detection matrix for multitemporal filtering and change analysis of SAR and PolSAR image time series. ISPRS Journal of Photogrammetry and Remote Sensing, http://dx.doi.org/10.1016/j.isprsjprs.2015.02.008.

Lee, J. S., Grunes, M. R., \& Pottier, E. (2001). Quantitative comparison of classification capability: Fully polarimetric 
versus dual and single-polarization SAR. IEEE Transactions on Geoscience and Remote Sensing, 39(11), 2343 - 2351.

Lee, J.-S., Grunes, M. R., \& Pottier, E. (2001). Quantitative comparison of classification capability: fully polarimetric versus dual and single-polarization SAR. IEEE Transactions on Geoscience and Remote Sensing, 39(11), 2343 - 2351.

Li, X., \& Yeh, A. G. (2004). Multitemporal SAR images for monitoring cultivation systems using case-based reasoning. Remote Sensing of Environment, 90(4), 524 - 534.

Lillesand, T. M., Kiefer, R. W., \& Chipman, J. W. (2004). Remote Sensing and Image Interpretation (5th Ed.). Wiley International.

Malenovský, Z., Rott, H., Cihlar, J., Schaepman, M. E., GarcíaSantos, G., Fernandes, R., \& Berger, M. (2012). Sentinels for science: Potential of Sentinel-1, -2, and -3 missions for scientific observations of ocean, cryosphere, and land. Remote Sensing of Environment, 120, 91 - 101.

Manavalan, R., Rao, Y. S., Krishna Mohan, B., Venkataraman, Ganesh, \& Chattopadhyay, Subrata. (2013, 2013). Landuse/landcover based flood area assessment using L-and Cband SAR data of coastal region of Andhra Pradesh, India. Paper presented at the Asia-Pacific Conference on Synthetic Aperture Radar (APSAR).

Mitraka, Z., Chrysoulakis, N., Kamarianakis, Y., Partsinevelos, P., \& Tsouchlaraki, A. (2012). Improving the estimation of urban surface emissivity based on sub-pixel classification of high resolution satellite imagery. Remote Sensing of Environment, 117, $125-134$.

Muro, J., Canty, M., Konradsen, K., Hüttich, C., Menz, G., Nielsen, A. A., ... Thonfeld, F. (2016). Identification of Dynamic Cover Types in Wetlands by using Multitemporal Crosspolarized Sentinel1 Images. Presented at the Living Planet Symposium, ESA.

Niu, Xin, \& Ban, Yifang. (2013). Multi-temporal RADARSAT2 polarimetric SAR data for urban land-cover classification using an object-based support vector machine and a rule-based approach. International Journal of Remote Sensing, 34(1), 1-26.

Parihar, N., Das, A., Rathore, V. S., Nathawat, M. S., \& Mohan, S. (2014). Analysis of L-band SAR backscatter and coherence for delineation of land-use/land-cover. International Journal of Remote Sensing, 35(18), 6781-6798.

Pierce, L. E., Bergen, K. M., Dobson, M. C., \& Ulaby, F. T. (1998). Multitemporal land-cover classification using SIR-C/XSAR imagery. Remote Sensing of Environment, 64(1), 20 - 33.

Pierce, L. E., Ulaby, F. T., Sarabandi, K., \& Dobson, M. C. (1994). Knowledge-based classification of polarimetric SAR images. IEEE Transactions on Geoscience and Remote Sensing, 32(5), $1081-1086$.

Plank, S. (2014). Rapid Damage Assessment by Means of Multi-Temporal SAR - A Comprehensive Review and Outlook to Sentinel-1. Remote Sensing, 6, 4870 - 4906. http://doi.org/10.3390/rs6064870

Powell, R. L., Roberts, D. A., Dennison, P. E., \& Hess, L. L. (2007). Sub-pixel mapping of urban land cover using multiple endmember spectral mixture analysis: Manaus, Brazil. Remote Sensing of Environment, 106(2), 253 - 267.
Qi, Zhixin, Yeh, Anthony Gar-On, Li, Xia, \& Lin, Zheng. (2012). A novel algorithm for land use and land cover classification using RADARSAT-2 polarimetric SAR data. Remote Sensing of Environment, 118, 21-39.

Qi, Zhixin, Yeh, Anthony Gar-On, Li, Xia, \& Zhang, Xiaohu. (2015). A three-component method for timely detection of land cover changes using polarimetric SAR images. ISPRS Journal of Photogrammetry and Remote Sensing.

Saatchi, S. S., Soares, J. V., \& Alves, D. S. (1997). Mapping deforestation and land use in Amazon rainforest by using SIR-C imagery. Remote Sensing of Environment, 59(2), 191 - 192.

Schott, J. R. (2009). Fundamentals of Polarimetric Remote Sensing (Vol. TT81). Bellingham, Washington: SPIE Press.

Sentinel-1 Team. (2013). Sentinel - 1 User Handbook. User Handbook.

Sole, A., Albano, R., PascaleL, S., Giosa, L., Sdao, F., \& Sivertun, Å. (2011). A decision-making support model for systemic vulnerability assessment in urbanized areas. In Urban and Regional Data Management (Vols. 1-0, pp. 211-219). CRC Press. Retrieved from http://dx.doi.org/10.1201/b11647-21

Taubenböck, H., Esch, T., Wurm, M., Roth, A., \& Dech, S. (2010). Object-based feature extraction using high spatial resolution satellite data of urban areas. Journal of Spatial Science, 55(1), 117-132.

Taubenböck, H., Roth, A., \& Dech, S. (2007). Linking structural urban characteristics derived from high resolution satellite data to population distribution. Urban and Regional Data Management, 35-45.

Taubenböck, H., Wegmann, M., Roth, A., Mehl, H., \& Dech, S. (2009). Urbanization in India-Spatiotemporal analysis using remote sensing data. Computers, Environment and Urban Systems, 33(3), 179-188.

Thiel, C., Cartus, O., Eckardt, R., Richter, N., Thiel, C., \& Schmullius, C. (2009). Analysis of Multi-Temporal Land Observation at C-Band. Presented at the IGARSS, IEEE.

Torres, R., Snoeij, P., Geudtner, D., Bibby, D., Davidson, M., Attema, E., Brown, M. (2012). GMES Sentinel-1 mission. Remote Sensing of Environment, 120, 9-24.

Ulaby, F. T., Kouyate, F., Brisco, B., \& Williams, T. H. L. (1986). Textural information in SAR images. IEEE Transactions on Geoscience and Remote Sensing, 24(2), 235 245.

Wang, F. (1990). Fuzzy supervised classification of remote sensing images. IEEE Transactions on Geoscience and Remote Sensing, 28(2), 194-201.

Wegmuller, U., Santoro, M., Werner, C., \& Cartus, O. (2015). On the Estimation and Interpretation of Sentinel-1 Tops InSAR Coherence. In Dragon 3 Mid Term Results Symposium.

Werner, Adrian, Storie, Christopher D., \& Storie, Joni. (2014). Evaluating SAR-Optical Image Fusions for Urban LULC Classification in Vancouver Canada. Canadian Journal of Remote Sensing, 40(4), 278-290.

Yang, L., Xian, G., Klaver, J. M., \& Deal, B. (2003). Urban Land-Cover Change Detection through Sub-Pixel 
Imperviousness Mapping Using Remotely Sensed Data. Photogrammetric Engineering \& Remote Sensing, 9(8), 1003 1010 .

Yeh, Anthony Gar-On, \& Qi, Zhixin. (2015). Short-Interval Monitoring of Land Use and Land Cover Change Using a Time Series of RADARSAT-2 Polarimetric SAR Images Space-Time Integration in Geography and GIScience (pp. 353-371): Springer.

Zhang, Hongsheng. (2015). Impacts of Feature Normalization on Optical and SAR Data Fusion for Land Use/Land Cover Classification. IEEE Geoscience and Remote Sensing Letters, 12(5), $1061-1065$.

Revised June 2015 